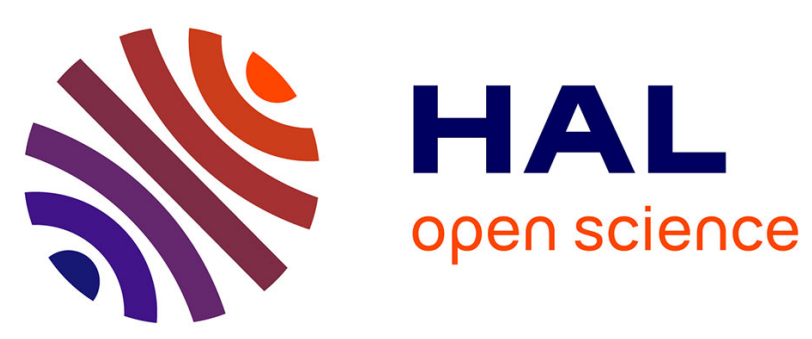

\title{
Wayfinding Behavior in India
}

\author{
Naveed Ahmed
}

\section{To cite this version:}

Naveed Ahmed. Wayfinding Behavior in India. 15th Human-Computer Interaction (INTERACT),

Sep 2015, Bamberg, Germany. pp.522-530, 10.1007/978-3-319-22668-2_40 . hal-01599893

\section{HAL Id: hal-01599893 \\ https://hal.inria.fr/hal-01599893}

Submitted on 2 Oct 2017

HAL is a multi-disciplinary open access archive for the deposit and dissemination of scientific research documents, whether they are published or not. The documents may come from teaching and research institutions in France or abroad, or from public or private research centers.
L'archive ouverte pluridisciplinaire HAL, est destinée au dépôt et à la diffusion de documents scientifiques de niveau recherche, publiés ou non, émanant des établissements d'enseignement et de recherche français ou étrangers, des laboratoires publics ou privés. 


\title{
Wayfinding Behavior in India
}

\author{
Naveed Ahmed \\ Industrial Design Centre, Indian Institute of Technology Bombay, Mumbai, India
}

ahmed.naveed@yahoo.co.in

\begin{abstract}
India is highly heterogeneous in the way cities are laid out; the way people use landmarks and how certain cultural aspects affect wayfinding. These factors influence the design of maps and navigation systems.

Users from Mumbai and Rajasthan were interviewed to explore such implications and find design opportunities. These users had low education levels and needed to find addresses on a regular basis. The study was centered on the Indian context.

People in India rarely use maps for navigation. They rely primarily on asking around and navigate using landmarks. The landmarks people use during this are prominent but sometimes highly volatile and ad hoc like cows and people sitting on street corners. Some of these landmarks may not necessarily always be popular. While inquiring about the route, people repeatedly seek reliable sources en route, to validate the information they have. Other findings during the study include people's preferences in using maps and concerns while seeking directions. Mental models of people also affect the way people navigate and exchange the wayfinding information. Some of these are very specific to the Indian context.

In the end, we also discuss how these findings will affect the design of navigation and (culture-centric) wayfinding systems.
\end{abstract}

Keywords. Navigation, wayfinding, India, culture, behavior

\section{Introduction}

Navigation and wayfinding are an integral part of modern lives. Wayfinding is the process of gathering required information and making decisions about the direction of travel. This includes determining one's location in comparison to the destination or a nearby location.

According to Golledge, wayfinding is concerned principally with how the route is structured rather than the environment through which the path passes [1], but in a modern city where life is affected by factors like traffic congestion, multitasking, etc., the path and the environment equally impact wayfinding and navigation.

The process of wayfinding is affected by a person's physical, intellectual abilities, socio-cultural background, gender, etc. [2] [3] and in turn adversely affects the design of wayfinding systems. In India, where people rely primarily on asking around, these 
factors even determine if the information conveyed is right or wrong. People have apprehensions and preferences in asking around. People take time to decide whom to ask, when to ask and how often to ask.

Along with these, mental models and perceptions of a particular place determine how people store information about routes and how they are conveyed to other people. As navigation is a spatiotemporal process, these perceptions change based on the stimuli the traveler receives at the moment [4]. This results in creation of newer wayfinding strategies and routes, than that already exist [5].

India as a country is highly heterogeneous in the way cities are laid out and the way people use landmarks in the absence of proper road signage. Cultural aspects specific to this country determine how wayfinding instructions are exchanged. These affect the way maps and navigation systems are designed. The studies reported in this paper are an attempt to explore such implications and find design opportunities.

In a map, landmarks like buildings, trees, statues, etc. and topographical features like hills and elevations act as referential points to know one's position or to orient oneself. These are marked on a physical map to aid navigation. But in India, where very few people use printed maps, landmarks play a pivotal role and wayfinding is done by asking around for these landmarks en route. Added to these are many biases of how people provide these instructions that affects the process of wayfinding.

The findings of user studies have been presented further and possible implications that affect the design of wayfinding systems in a country like India are discussed.

\section{Methodology}

As part of a Master's project, we tried to understand people's wayfinding habits, how people use existing solutions and conditions under which these have failed. The findings in this paper are the result of user studies conducted during the project.

To understand the process of wayfinding, users who did this on a regular basis were interviewed. This included delivery personnel, intra- \& inter-city drivers and repair technicians. Most of the users had low education levels and needed to find addresses on a frequent basis. People who used existing solutions regularly were also interviewed to understand their usage behavior.

Users were chosen based on their vocation and availability. In all, 15 people were interviewed and most of them were in the age group of 25-35 and have lived in city suburbs most of their lives. Of these, 10 were men and 5 women. Finding unique users was time-consuming as these cohorts operate within fixed areas in the city. The users had low familiarity with using a computer but used smartphones regularly.

The project also took into account and extended the outcome of a study on wayfinding by design students at IIT Bombay, which involved interviews with 47 people in towns near Mumbai.

Indian cities are structured differently and hence users were chosen from geographically different regions to obtain diversity in inputs-two of which were inter-city drivers from Jaipur (Rajasthan) and the rest from Mumbai and its suburbs. 
Contextual inquiries were conducted with the users to know their working processes, how they find addresses, their recent journeys and the hurdles they face. As part of unstructured studies, something similar to the master-apprentice model was followed. We chose a few destinations and asked random people (en route) for ways to reach the place. In both the cases, the responses were recorded and later analyzed through affinity mapping.

Towards the end of the primary studies, a separate set of 5 people were interviewed to understand mental models of sketching and representation of familiar routes.

The project resulted in the conceptualization of a navigation mechanism using schematic maps and photographs of landmarks. This has not been discussed in this paper.

\section{$3 \quad$ Findings}

The findings of the user studies, discussed below, affect the way maps are designed, particularly in the Indian context.

\subsection{Landmark Information}

As India is not a very map-savvy culture, landmarks have always played an important role in wayfinding. In our studies, even users of online maps mentioned that they checked major landmarks on their route before starting the journey.

Prominent physical structures like buildings and trees are commonly used as landmarks. Sometimes the color of a building is more important than the building itself. But this is mainly in case of larger roads.

In smaller streets, the choice of landmarks changes completely. People use garbage bins, broken walls, nullahs and even volatile entities like road-side vendors, people sitting on street corners, potholes and cows as reference points. Here, religious structures like minarets and nishan sahib which are specific to an area are also used.

Some landmarks from user studies (specific to India): Mother dairy outlets (milk booths), trees, color of buildings, slums, electric poles, banyan trees, fish markets, post-boxes, tiny temples and dargahs under trees, rickshaw stands, road-side shops (like ironing store, cobblers, cycle shop, betel nut \& cigarette shops), street vendors, drainages, broken walls, garbage bins, chabutras, political party offices, police outposts, policemen, gated communities (like chawls), minarets, electric transformers, religious flagpoles (e.g. nishan sahib), prominent cultural residences (like pols in Ahmedabad), public toilets, grocery stores, flyover pier numbers are amongst other prominent locations.

This list is not exhaustive and is in no specific order. 


\subsection{Whom to ask?}

Though people rely heavily on asking around to find the address right, they are often not sure about whom to ask for directions. People solve this problem by relying on 'seemingly-trusted' persons and 'possible' providers of information.

Well-dressed and older people are presumed to be more trustworthy than others. Autowallahs and panwallahs ${ }^{1}$ are considered more reliable as they are usually local to an area and might know the place better. But some users said that autowallahs often refused or provided wrong information.

A user also mentioned a case where school students misguided him and he had to find his route all over again.

Women prefer asking other women. This striking feature was noticed more than once in our studies. According to Lawton and Kallai, women are more likely to experience wayfinding anxiety than men. This could be due to the cultural upbringing resulting in a feeling of insecurity and vulnerability, especially in unfamiliar areas. Studies have also shown that women use different wayfinding strategies than men [3].

People also seek multiple sources (en route) to verify and validate the information they have been provided with. But this may sometimes cause more harm than good, as people have their own perceptions and understanding of a route and excessive verification by the information seekers (info-seekers) might lead them astray.

\subsection{Mental Models}

People create mental models and have perceptions in navigation and wayfinding too. Users construe a route without any turns as a straight road. They do not perceive a curve unless it is at a sharp angle. Users subconsciously perform rectilinear correction of the path by ignoring the minor bends and curves.

When asked to draw the route between two points they travel regularly, users usually did a correction in the path. If the route had no major turns, it was drawn as a straight road. Bends were ignored. People mentioned details only when the path involved too many turns. They sketched finer details only when they got closer to the destination.

High-speed parts of the road were drawn straighter than the low-speed ones.



Fig. 1. On the left are sketches by people and on the right are screenshots from Google Maps.

1 An autorickshaw driver is a autowallah and a panwallah is a betel nut seller. Both of these can be found in most of the street corners in India. 
However, the nature of sketch might change depending upon how familiar the route is to the person. Regular commuters, infrequent travelers and first-time travelers will have a different perception of the same route. Understanding the difference in their mental models will require further study and inquiry into this subject.

Kevin Lynch in his book, The Image of the City, talks about how landmarks should be created in a city so that people can create easy mental maps of the city they live in and of the routes they traverse (called imageability and visibility) [6]. So, these mental models are also affected by the layout and structure of the city.

For example, cities like Chandigarh in India follow a grid (also called gridiron) structure, while New Delhi has a radial structure and places like Hyderabad which have evolved organically, do not follow any fixed structure. As grid cities are organized in rectilinear roads, referring to and recalling routes is easier, than in case of an organic or non-grid layouts.

Roads look different at different times of the day. Landmarks also appear different because of traffic and light conditions which vary greatly depending on the time of the day. The perception of a route, hence, also depends on several natural and manmade variables.

\subsection{Progressive Discovery}

People find their way through progressive discovery. Progressive discovery is like progressive disclosure which is an interaction design technique where only the important and primary information is disclosed initially and the rest of it is provided on demand [7]. Similarly, users divide their journey into shorter milestones and once they reach each of these, they inquire for further directions.

Depending upon proximity to the destination, information providers (infoproviders) also provide directions progressively. They advise the info-seekers to reach a certain point ahead and then ask further. Certain info-seekers and even infoproviders felt that verbal directions are complex and confusing. Hence, they followed progressive disclosure of information intuitively. In short, both info-seekers and infoproviders first search for larger information and get into finer details only when they are closer to the destination.

This is true even in case of some Google Maps users who obtained the approximate route to their destination online and got into micro details of reaching their destination by asking around.

\subsection{Size of the road}

People feel it is easier to ask for directions on larger roads than in the inner streets. This may be because of progressive discovery. People seek major landmarks while on the larger roads and get into intricate details only when they get closer to their destination. Intricate details mean specificity and finding them is more difficult.

Info-providers would generally know the bigger picture better than the finer details, compared to inner streets where the volatile landmarks are known only to those who know the area well. 


\subsection{Measuring Distance}

People use several indigenous and ingenious methods to measure distance. Locally available data such as the number of buildings, telephone poles, traffic signals and trees are often used. In some cases, the distance is measured by the amount of fare charged by the bus or any available mode of public transport. In rural areas, people also use the number of villages between the starting point and the destination as a measure of distance.

The number of route options to reach the destination depends directly on the distance between the source and the destination. The layout of the city also affects the number of routes available. A grid structure has lesser route options to complete a journey compared to a radial or organic layout [8]. One user mentioned that grid meant more travel whereas it was easier for him to find shortcuts in a city with a nongrid layout. As a result, he perceived travel times to be lower in such (non-grid) cities.

\subsection{People do not prefer online maps}

Being a society where maps are sparsely used for wayfinding, online aerial maps are something that users in India find difficult to adapt to. Traditional GPS-based solutions evolved from aerial perspective of locations. But in India where use of traditional maps is low, digital solutions based on aerial perspectives may not always work.

Users mentioned that online maps do not contain adequate information for wayfinding. People in India usually find their way using landmarks and by asking around. This information is not readily available to them on the maps or easily accessible. Even if they find the right route, they could not backtrack or travel again on the same route without assistance. This created a negative bias towards online maps.

Landmark information was something they wanted maps to provide, so that they can remember the route even if they are not using maps during subsequent travel.

Some users were not comfortable using software for navigation, as they could not operate them easily. Anxiety during travel and unfamiliarity with the place and the use of software may contribute to this behavior.

Users were not very keen on continuously using mobile phones for maps as it was perceived as 'talking on the phone' by others. A user was once booked by traffic police for using mobile phone while the vehicle was waiting at a traffic signal. Also, solutions like Google Maps did provide audio feedback but it was difficult to listen to instructions in noisy traffic conditions.

\subsection{Usage of existing solutions}

Of all the users interviewed, five of them had used print maps and online solutions like Google Maps and Nokia HERE earlier.

One user (a European citizen) who used print maps extensively found it difficult to use them in India as they were not detailed and finding street names was not easy. This is due to improper and insufficient signage. He later resorted to asking around. 
A user felt that Google Maps provided information that was not completely reliable. He used the application primarily to know his current position and if the taxi was taking him on the correct route. But the app always re-routed based on the current position. There was no direct way to confirm the authenticity of his route.

Due to the shortest path strategy, the map applications sometime route user via smaller streets and villages, instead of the main roads or the highways. This confused users about the authenticity of the route provided. Users in such cases had to go back to asking people around to make sure they are on the right path. It leads to further anxiety when the app re-routes to a new route in an already unfamiliar path.

One user was gifted a dashboard console for his car a year back, but had stopped using it within a month. He did not find it useful as most of the travel was intra-city and it was too cumbersome to input data to find a route.

\section{$4 \quad$ Design Implications}

All the entities that form part of the wayfinding process seem to have some sort of uncertainty associated with them - may it be the mental models, the way people exchange information or the kind of landmarks that are used. In spite of all this, the seemingly-chaotic process works successfully, and for many users most of the navigation information becomes expendable after they cross a milestone during the journey.

In the findings so far, we also see that existing solutions failed due to various internal or external reasons like interface issues, poor infrastructure or specific requirements by users. Sometimes, as the profile of the user changed, so did their requirements.

Landmarks, big or small, are the key elements in the wayfinding process especially in absence of proper signage. And for a culture that navigates primarily on verbal onthe-go basis, a solution must seamlessly integrate landmark data and provide it along the route being traversed. Instead of an aerial view, the solution must be completely landmark-based that shows a ground-level view to the user.

Also in a country like India, where topographical changes are very frequent, care must be taken that landmark data is valid and correct at any given point of time. The solution must be flexible enough to accommodate the volatility of the landmarks. This will help in making the system more reliable.

People seek trustable sources and they will look for 'trust' in any solution. This has been clearly noticed in the user studies where people tried to seek reliable sources repeatedly. Creating trust into a non-human entity is something that would make or break the solution. As Progressive Discovery is an almost accepted behavior, it is not required that complete information is provided to the user in one go. Necessary information can be provided to the user to take him to the next intermediate point in his journey and he can take further decisions thereafter. The solution can have smaller milestones for people to achieve, like a game, leading to the final destination. This will help the user be assured that he is on the right path and also get a feeling of accomplishment. 
The kind of landmark information people use also has a major impact on the way data is collected for the solution. It would be easier to find data in the bigger context than the intricate street-level details. The details from the last mile of journey are the most important and if the solution fails at this stage it would render the whole exercise of wayfinding useless. The main aim is to create a solution that works for first-time users, as people would remember the route (even if vaguely) on subsequent travel.

There is also an opportunity to create solutions, which cater to different times of the day-mainly lighting conditions - to provide a seamless experience.

Human mind ignores minor bends and curves to create unique mental models. This feature can be incorporated in a map to provide the simplest of information, similar to a schematic map. Schematic maps are closest to mental models in terms of simplicity and have been used over the years for representing transit routes. E.g. the London Tube. Major turns and prominent topological features can be reproduced for guidance and to prevent errors. Users can concentrate on their route instead of the other details, if they are provided with simplest and only the necessary information.

It may not always be possible to create an ultimate solution. But these findings might lead to a solution for certain target groups like people with low-education levels or those unfamiliar with using maps, who amount to a fairly large and untapped part of the population in India.

\section{$5 \quad$ Future Work}

In the past few years, India has seen the emergence of professions like delivery, courier, cab and related door-to-door services. These require searching and finding addresses on a daily basis. Most of these professions do not require very high educational levels and hence people employed in these are not highly educated. (Low education levels here does not imply low literacy.)

People in these professions often possess smartphones but never use them beyond the employer-specified application. Cohorts like these, who underuse accessible technology, can be the primary focus to create a solution. This must also be done by keeping in mind the bottom of the pyramid to facilitate easy adoption amongst users with very less or no exposure to technology.

Further research would include making such applications more usable through newer technologies like text-less and aural interfaces.

Acknowledgements. I would like to thank my project guide Prof. Anirudha Joshi of Industrial Design Centre (IDC), IIT Bombay, for his critical feedback throughout. Faculty at IDC for their inputs during the project. Participants and friends who assisted me during the user studies. Anshumali Baruah and Ishneet Grover for the initial reviews. Umme Hani for the thorough proof-reading and suggestions during the making of this document. 


\section{References}

1 R. G. Golledge, Wayfinding Behavior: Cognitive Mapping and Other Spatial Processes, Johns Hopkins University Press, 1999.

2 P. Arthur and R. Passini, Wayfinding: People, Signs, and Architecture, Reprint ed., Focus Strategic Communications, Inc., 2002.

3 C. A. Lawton and J. Kallai, "Gender Differences in Wayfinding Strategies and Anxiety About Wayfinding: A Cross-Cultural Comparison," vol. 47, 2002.

4 D. R. Montello and C. Sas, "Human Factors of Wayfinding in Navigation," 2003.

5 S. Hunter, "Spatial Orientation, Environmental Perception and Wayfinding," IDeA Center, University at Buffalo, 2010.

6 K. Lynch, The Image of the City, The MIT Press, 1960.

7 J. Nielsen, "Progressive Disclosure," 4 December 2006. [Online]. Available: http://www.nngroup.com/articles/progressive-disclosure/.

8 J. Walker, "The power and pleasure of grids," 2010. [Online]. Available: http://www.humantransit.org/2010/02/the-power-and-pleasure-of-grids.html. [Accessed 26 May 2014].

9 Wikipedia, "Planimetrics," $2014 . \quad$ [Online]. Available: http://en.wikipedia.org/wiki/Planimetrics. [Accessed 24 May 2014]. 